\title{
HD-MTX/ARA-C Regimen
}

National Cancer Institute

\section{Source}

National Cancer Institute. HD-MTX/ARA-C Regimen. NCI Thesaurus. Code C140102.

A regimen consisting of high-dose (HD) methotrexate (MTX) plus HD cytarabine (AraC)

that can be used in the treatment of central nervous system (CNS) lymphoma and refractory or relapsed (RR) non-Hodg kin lymphoma (NHL). 